\title{
Stage III Hilar Cholangiocarcinoma AJCC v8
}

National Cancer Institute

\section{Source}

National Cancer Institute. Stage III Hilar Cholangiocarcinoma AJCC v8. NCI Thesaurus.

Code C134747.

Stage III includes: IIIA: (T3, N0, M0); IIIB: (T4, N0, M0); IIIC: (Any T, N1, M0). T3: Tumor invading unilateral branches of the portal vein or hepatic artery. T4: Tumor invading the main portal vein or its branches bilaterally, or the common hepatic artery; or unilateral second-order biliary radicals with contralateral portal vein or hepatic artery involvement. N0: No regional lymph node metastasis. N1: One to three positive lymph nodes typically involving the hilar, cystic duct, common bile duct, hepatic artery, posterior pancreatoduodenal, and portal vein lymph nodes. M0: No distant metastasis. (AJCC 8th ed.) 